\title{
A BASIC CONCEPTUAL STRUCTURE OF EVOLUTIONARY ECOLOGY
}

\author{
Rogério Parentoni Martins ${ }^{1}$

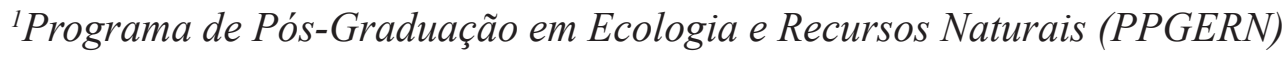 \\ Universidade Federal do Ceará (UFC)
}

\begin{abstract}
.
Concepts are linguistic structures with specific syntax and semantics used as sources of communicating ideas. Concepts can be simple (e.g., tree), complex (e.g., adaptation). The conceptual interrelationships and some evolutionary consequences upon which these interrelations are based will be addressed here. The evolutionary ecology is an area of research from the population evolutionary biology that deals mainly with the effect of positive natural selection on panmictic and structured populations. Environmental factors, conditions and variable resources in time and space, constitute the selective agents that act on the phenotypic and genotypic variation of populations in a single generation, could result in evolutionary adaptations, which are simply those traits that are most likely to confer survival and reproduction (evolutionary fitness) of the phenotypes that carry them in successive generations. The bases of adaptation are mainly genetic and transmitted vertically or horizontally. The phenotypic variance of the population is a conjoint consequence of the additive genotypic variance (heritability), nonadditive variance (dominance and epistasis), pleiotropy and the interaction between genotype and environment. The ability of the same genotype to respond to spatial environmental variations can result in phenotypic plasticity that manifests itself through reaction norms. The total phenotypic variation and its genetic and environmental components influence the ability of a population to evolve (evolvability).
\end{abstract}

Key words: evolutionary adaptation, evolutionary fitness, environmental factors, positive natural selection, evolvability

\section{INTRODUCTION}

Ecology in isolation is an area of scientific research that seeks to interpret evidence of phenomena resulting from interactions at different hierarchic levels of biological organization (individuals, populations, communities and ecosystems). The performance of interactive ecological processes (e.g., predation, competition and mutualism) and the influence of variable physical and chemical conditions (e.g., temperature, rainfall, organic and inorganic nutrients respectively) and the resources used by organisms (e.g., food items and breeding sites) on the structure and functioning of each of these levels interferes with immediately higher and lower levels and vice versa. In addition, ecology interfaces with other disciplines of biology, such as physiology, morphology, anatomy, behavior, biogeography, genetics and evolution, for example, as well as certain areas of mathematics and statistics, chemistry and physics, if we consider the just the natural sciences alone. This interface widens further if we take into account human ecology and its derivations in various human sciences (e.g., anthropology, sociology and philosophy).

All of these disciplinary interfaces have their own theoretical foundations and scientific applications, such as energy flow in a forest (energy ecology), inorganic pollutant flow in an aquatic food web (chemical ecology), and the effect of natural selection on population fitness (evolutionary ecology). Thus, each of these disciplines can be treated independently. From this perspective, the object of this text is to conceptually characterize the evolutionary ecology of populations, whose theoretical basis is natural selection and the associated genetic-evolutionary processes. The theoretical and empirical integration of ecology and evolution expands the possibilities of understanding, for example, the evolutionary consequences of natural selection on the structure and functioning of ecological communities. Such consequences can also occur at other levels of organization, such as individuals, populations, ecosystems, landscapes, biomes and biosphere.

Since positive natural selection (hereafter, positive natural selection whenever natural selecion is mentioned in the text), is an eminently ecological process that can result in adaptive and evolutionary changes, the interaction between ecology and evolution is more than necessary to understand how ecological processes operate together with genetic-evolutionary processes, the result of which is the diversification and organization of life. As a result, evolutionary ecology is a broad area of scientific research in which researchers with different approaches aim to understand the results of ecological and 
genetic-evolutionary phenomena and processes in terms of differentiating individuals, populations, species, communities and ecosystems at distinct spatial scales.

Covering such an extensive multivariate topic in just one such article is an almost impossible task, unless it were to make use of simplifications that could compromise the understanding of what evolutionary ecology really is. Even if it were possible to accomplish this task in more detail, there are already publications written by experts that address the specificities and concepts of this area of research, such as natural selection, phenotypic variation, evolutionary fitness (differential survival and reproduction), evolutionary adaptation, evolvability, environmental conditions and usable resources, characteristic, trait, heritability, additive and nonadditive genetic variance (dominance and epistasis), pleiotropy, environmental variance, panmictic and structured populations, phenotypic plasticity and reaction norm (Fox et al., 2001; see Table 1 and Figure 1 in this text).

In the case of this text, just indicating what would be the qualitative and quantitative methodologies used to gain knowledge of the phenomena related to this area of research would be insufficient to characterize its nature satisfactorily. Nor is it enlightening to say that evolutionary ecology is the junction of ecological research (e.g., species interactions) and genetic-evolutionary research (e.g., evolution of the genetic structure of populations). It would be a little better to say that evolutionary ecology is the quantitative study of natural selection in the field.

It is indeed correct to say that natural selection appropriately concerns evolutionary ecology since selection can promote evolutionary fitness (survival and reproduction) of individuals in a population whose traits may be favored or disadvantaged as a result of the interaction between phenotypic, genotypic and environmental variation. We can measure, for instance, the opportunity of selection (total potential of selection to act on a population, measured by the variance of relative fitness), direction (directional, stabilizing and disruptive selection, models applied to continuously distributed traits) and intensity (differential selection measured by scaled trait values, called the z-score). The z-score is obtained, for example, by measuring bird beak sizes in a sample of the beak population, minus the average of these measurements divided by the standard deviation of the mean; however, obtaining these measurements (see Brodie III et al.,1995; Linnen \& Hoekstra, 2009 for details of these and other another measurements). To characterize aspects of natural selection is only part of the studies performed by evolutionary ecologists

Another topic of interest to evolutionary ecologists is the evolutionary consequences of natural selection involving monogenic genetic mechanisms, gene interactions (pleiotropy) that interfere with phenotypic expression, additive genetic variance (heritability) responsible for phenotypic similarity between parent and offspring, nonadditive genetic variance that also interferes with phenotypic expression through dominance and epistasis, and genotype-environment interactions. These mechanisms precede, and are in various ways involved in, the occurrence and maintenance of evolutionary adaptations.

While there are other important areas of ecological-evolutionary research, such as ecology and evolution of specialist and generalist organisms, evolutionary ecology of sex and gender, coevolution, evolution of senescence and evolutionary ecology of life cycles, I have chosen to address the basic concepts and processes (natural selection, phenotypic variation, evolutionary fitness, evolutionary adaptation, evolvability, environmental conditions and usable resources, characteristic, trait, heritability, additive genetic variance and nonadditive genetic variance, dominance and epistasis, pleiotropy, environmental variance, panmictic and structure populations, phenotypic plasticity and reaction norm), as they are common and fundamental to all themes addressed by evolutionary ecology (see Fox et al., 2001; Table 1 and Figure 1 in this text). Therefore, what will come further ahead and prior to a critical conceptual analysis, such as Pigliucci \& Kaplan (2006), will be a description of these basic concepts, their definitions and interrelationships, which integrate this area of scientific research. First, however, I describe the role of natural selection in environmentally stable and unstable environments, given that selection is the most important causal process responsible for the adaptive evolutionary changes of organisms.

For selection to work, it is unnecessary for the target trait of selection to be a priori heritable, since some researches confuse selection with the evolutionary consequences of selection (e.g., Endler 1985; Fairbairn \& Reeve 2001). Selection acts on population phenotypic variation over the course of a single generation. Only after selection has taken place and the selected trait is heritable, persisting over several generations, can we say that an adaptation has evolved. Therefore, a trait selected in only a single 
generation can only be considered an evolved adaptation through selection if the adaptation contributes to differential survival and reproduction of individuals of several successive generations, in ecologically stable or unstable environments.

Ecologically stable environments are those in which their conditions, such as average temperature or rainfall for example, remain seasonally predictable (i.e., for several successive years). Furthermore, in these types of environments, the occurrence of ecological interactions, such as mutualism, predation or competition, must also remain seasonally stable. However, for the maintenance of species richness and relative abundances of a taxocenosis (set of species in the same supraspecific taxonomic category, e.g., birds) or a guild (set of species, regardless of the taxonomical category to which they belong, that similarly use the same type of resource, e.g., frugivorous birds and bats), in addition to environmental conditions remaining stable, resource availability must also be seasonally predictable. This is especially true when it comes to specialist organisms, which depend on the use of specific resources such as preferred types of food or places required for breeding.

An example of specialization with regard to breeding site are species of solitary bees that only nest in nests already prepared in cavities dug in the ground by another species of co-occurring solitary bee. Females of the first species can usurp the newly dug nest of the other, and although it is almost ready to receive the egg form the bee that dug it, the usurper will continue to prepare it in a very complex manner using different materials (soil, cut leaves, soil pellets left by ants around anthills) to obstruct the cavity after performing oviposition, a task that can take a few hours of activity of a female in a single nest. However, it is expected that, as a specialist, it will be regionally abundant if the "host" bee, hypothetically, is widely distributed. This interaction between the two co-occurring species is especially interesting as a study system on adaptation, not only at the local level (Martins \& Almeida,1994), but throughout the geographic range because in fact the "host" bee in question is widely distributed (see Silveira et al. 2002; Moure \& Melo 2012).

Equally important is to understand the evolutionary ecology of populations of organisms that live in unstable and unpredictable environments, where temporal variation in environmental conditions and resources may select specific and peculiar adaptations as responses to conditions and resources that limit population growth. Diapause is an example of this kind of adaptation; that is, the disruption of the development of immature individuals and the activity of adult individuals that occurs largely in certain insects living in temperate or tropical regions. Diapause allows the synchronization of development among individuals in whom development has been temporarily interrupted and conditions and resources to survival and reproduction, thereby providing continuity between successive generations in space and time (Martins \& Barbeitos, 1991; Martins et al., 1992; Martins, 1993; Martins et al., 2017). One of the evolutionary strategies that can lead to diapause is bet-hedging. Simply put, bet-hedging is the seasonal or annual dispersal of reproductive effort to maximize the survival and reproduction of individuals in unpredictable changing environments (see Martins et al., 1992, for an example of a bee species and its parasites).

On the other hand, the various human activities currently being performed on the planet (e.g., introduction of exotic species, construction of mega-agricultural enterprises, large hydroelectric plants etc.) cause changes that can lead to extinction, particularly of species adapted to certain types of resources and conditions in the ecosystems where they live. The destruction of habitats, where such species occur, due to human activities, is one of the main reasons for local extinction. For these reasons, certain ecologically stable environments that have evolved thousands of years ago, such as some still little-altered forests in the Amazon region, can, under intense modification and in a relatively short period of time, become ecologically disrupted (e.g., extinction of pollinators and dispersers of seeds) leading to irreparable losses in the structure and function of native fauna and flora. In this respect, studies of evolutionary ecology are also of importance from the point of view of conservation and management of biodiversity in altered areas due to human activities. Particularly important are studies that determine the thresholds of the ability of populations to evolve (evolvability or evolutionary adaptability) under the impact of human activities, but also in locations where there is little impact. Comparative studies of this nature are important to support species and habitat conservation and management plans.

Finally, in order to understand how evolutionary ecology was constituted, we cannot do without exploring what would be the main historical antecedents that resulted in its establishment as an important area of research in evolutionary biology. However, before beginning the brief discussion of the historical 
background of evolutionary ecology, it is necessary to inform that the interrelationships between the concepts that form the basic conceptual framework of evolutionary ecology, such as the structure of evolutionary biology from the point of view of phenotypic plasticity (Martins, 2018), will be described through a conceptual map (Figure 1). The conceptual map is a useful tool for visualizing interrelationships among concepts that characterize a research area or program. In this way, I hope that readers can, at an introductory level, get at least an idea of the complexity covered by evolutionary ecology from the description of the basic concepts and the interrelationships among them, without needing to go into detail about each of the sub-research topics described at the beginning of this introduction.

\section{Brief Historical Background of EVOLUTIONARY ECOLOGY}

Here I only intend to provide the main episodes of the history of evolutionary ecology, mainly to relate the main researchers and ideas that contributed to the conceptual and empirical scientific development of the area in its current form. I begin by tracing a brief historical course of the idea of evolution.

The western origin of the idea of evolution is attributed to the pre-Socratic philosopher Anaximander of Miletus, the first to devise a theory of evolution similar to that of Darwin (Trevisanato, 2016). Anaximander influenced Aristotle, one of the greatest philosophers-naturalists of the west (Osborne, 1913), who some 2,000 years ago had already elaborated his own theory of evolution, by organizing animals into inferiors and superiors (Dunn, 2006). By that time Aristotle already recognized the principle of natural selection, yet had little understanding of it (Darwin, 1990). Nevertheless, Aristotle's scientific influence on biology was maintained for a little over 2,000 years until the so-called "Darwinian revolution" (Mayr \& Provine, 1998, and references therein). The Darwinian revolution consisted of the integration of Mendelian genetics with natural selection and quantitative genetics, as well as contingencies that could cause evolutionary change under constrained conditions, such as genetic drift. One of the forerunners of this integration, Sewall-Wright, proposed a mathematical model called the "shifting balance theory" to explain how the dynamics of evolutionary change occur through the combined action of selection and genetic drift. In other words, according to this model, genetic drift can only explain the occurrence of adaptations by acting in conjunction with natural selection (Charlesworth et al., 2017). The artistic conceptions of how selection and genetic drift should act on genotype frequency of populations also came from Sewall-Wright. These conceptions were intended to reach a broader audience, especially those biologists interested in evolution but little versed in mathematics (such as the author of this text), given that the mathematics employed by Sewall-Wright to represent the dynamics of evolution was very complex. There were two pictorial representations conceived by the evolutionist: fitness surface and adaptive landscape. The first represents the selection action on the frequency of individual alleles while the other represents the selection action on the average fitness of populations of genotypes. The impact of these pictorially characterized ideas was substantial and their representations were used in publications by leading evolutionary biologists, such as T. Dobzhansky and G. Simpson (see Pigliucci \& Kaplan, 2006, for a discussion of the history and inadequacy of these visual metaphors introduced by Sewall-Wright to explain the dynamics of the evolutionary process through the "shifting balance theory").

Going back in history, what characterized the revolution caused by Darwin/Wallace was the proposition of natural selection as the process responsible for producing adaptations, speciation and species diversification. In addition, Darwin promoted the link between ecology and evolution by identifying resource competition as the main causative agent of natural selection, that is, the promoter of adaptations and species diversification (Chapter 3 of Origin of Species in many editions). However, as is well known, Darwin ignored details of how a selected trait would be passed on to other generations. In his day genetics was not so developed; even a strong opponent of the idea of natural selection as the generator of adaptations was geneticist Hugo De Vries (one of the important precursors of genetics) with his mutational theory (see Mayr \& Provine, 1998, for details). De Vries proposed that evolutionary changes would result in direct response to the occurrence of mutations, without the need for intervention of natural selection. Obviously, with the development of genetics from Mendel's discoveries, and later from advanced studies, it has become clear that the evolution of adaptations is consistent with neo-Darwinian theory, excluding the possibilities of evolution through 
mutations alone or through inheritance of acquired characters as proposed by Lamarck (Charlesworth et al., 2017).

The connection between ecology (natural selection) and evolution thus happens through the processes of transmission of selected traits to subsequent generations (adaptations). Since selection works, as I explained earlier, the question now turns to how these selected traits are transmitted to subsequent generations; that is, what are the genetic (and non-genetic) processes by which they are transmitted. The classic process of genetic transmission of traits is through intergenerational gene sharing, which is responsible for the configuration of the selected characteristics. In other words, each inherited trait is determined by the interaction of at least one gene and the interaction of two alleles transmitted by the parents. This is the classic Mendelian mechanism of particulate transmission of hereditable characteristics (vertical gene transfer). However, genes may be transmitted, for example, by horizontal transmission of genetic material, as occurs between many single-celled organisms to certain multicellular organisms (e.g., bacteria to bacteria and bacteria to plants). There is also transmission through the nutrition that the female provides to progeny, such as the case with mammals, for example, by breast feeding or via blood stream, the processes of which differ from the so called maternal cytoplasmic inheritance or maternal effect. By this latter process, genetic material contained in mitochondria and plastids, for example, is transmitted to the progeny via egg cytoplasm in animals and plants, respectively (for further conceptual clarification see Wolf \& Wade, 2009).

In addition, there are also direct environmental influences (epigenetic mechanisms) that alter the phenotypic expression of sections of DNA. At least theoretically, these altered DNA strands, by methylation for example, can be replaced by a few multiple mutations by natural selection. Thus, although they are independent processes, epigenetics and natural selection may be complementary in their role of producing adaptations (Nikshawa \& Kino 2018). However, there are a number of unresolved difficulties about the possible effectiveness of epialleles as sources of variation that produce adaptations regardless of the role of natural selection. Two of these difficulties, among others, are (1) accounting for how many generations inherited epigenetic markers persist and are stable enough to influence evolutionary change; and (2) determining whether inherited epi- genetic changes are an important source of adaptive changes compared to changes in the sequence of DNA. Charlesworth et al. (2017) discuss in detail these and other difficulties which, at the present level of knowledge, prevent epigenetic modifications from having a status similar to natural selection in producing adaptive changes in a large number of species of animals, plants and microorganisms, as has been repeatedly demonstrated in the field (see Endler, 1986).

A distinction must be made between positive or adaptive natural selection and purifying or negative selection. The first results in evolutionary adaptations (addressed in most of this text) while the other means the elimination of deleterious alleles form a population. It is also useful to differentiate between the evolutionary consequences of soft and hard selection, which are types of adaptive selection. Both of these models (soft and hard selection) consider the environment in which the population lives as consisting of two or more habitat types among which the total population is subdivided. Also, with both of these types of selection, individuals spend part of their life span in one of the habitats, isolated from individuals in the other subpopulations, while another part of the lifetime of these individuals is spent mixed with the individuals of the total population. Soft selection is the type of selection that occurs during the time individuals are isolated in one of the habitats, so selection acts dependent on the conditions and resources of that habitat they are, in other words, selection will be dependent on the density and frequency of certain genotypes of individuals cohabiting the same habitat. On the other hand, hard selection occurs at the total population level. This means that selection regulates population size regardless of the density and frequency of certain genotypes (Débarre \& Gandon, 2011). Examples of these two types of selection are experimental studies with guppies conducted in habitats where predation on these fish is severe and in other habitats where predation on them is low. The results of these two predation regimes are the evolution of distinct adaptations (see Reznick, 2016, for details).

Since I didn't even find an example of hard selection in nature, I asked David Reznick if he could give me an example. He answered me: "I think pesticide use and the associated evolution of pesticide resistance could be qualified as hard selection because all individuals in the transmission region would live or die as a function of resistance, regardless of consideration of ecological variables such as population density, resource availability or the presence of other 
species. But this is not what we consider "natural" selection. It can be argued that the evolution of industrial melanism (lighter versus melanic moths) is hard selection, because any individual who does not match the background color of the substrate will be more susceptible to attack by predatory birds. Increased numbers of predated moths are a function of predators' visual acuity. But in fact, I believe this interpretation would be an oversimplification. The efforts that predators invest in prey hunting will be a function of their abundance and the abundance of alternative preys. If moths became rare due to predation and some more abundant alternative prey attracted more attention, then the relative fitness of previously predated moths would probably change. This is where frequency and density dependence come into play (which is characteristic of soft selection, my addition). I think it would be difficult to find a real-world circumstance that could be characterized exclusively as hard selection, even if that is the way we teach evolution to undergraduate students".

However, this is a good example of how a logically correct model can be attractive to theorists, but whose empirical validation in nature face serious constraints, unlike the soft selection model.

Although population ecology and population genetics formally began at about the same time, both areas of research pursued independent paths without effective collaboration between them for about three decades (Hairston Jr. et al., 1970). Population genetics worked with the definition of evolution as changes in the frequency of alleles between generations, currently considered by some researchers to be restricted (but highly successful), for example Pigliucci \& Kaplan (2006), but without necessarily taking into account individual phenotypic variation. In turn, researchers in ecology gave more importance to the effect of the environment on population demographic characteristics and population dynamics, without considering the effect of variation in allele composition among individuals, that is, considering all individuals as having invariant genotypes.

With respect to population fitness, population ecologists consider $(r)$ (intrinsic per capita population growth rate), the increase in number of phenotypes, as a measure of population fitness under given ecological conditions. Evolutionary geneticists similarly consider the Malthusian parameter $(m)$ (per capita growth rate of genotypes in a population) as a measure of population fitness. In the ecological context $m$ is equivalent to $r$, but in the evolutionary context, treated by Fisher, it referred to each possible genotype, which makes the Malthusian parameter $(m)$, in the evolutionary context, an imaginary rate because, when considering each possible genotype, the rate cannot be measured because it would be clearly necessary to have a much larger number of genotypes than the number of individuals in the population to express it (Hairston Jr. et al. 1970, and references cited therein).

Another possible cause for the lack of collaboration between population geneticists and population ecologists may have been that at the time it was still thought, as did Darwin, that the number of generations needed for evolutionary changes to take place (evolutionary time, ca. 500,000 generations) would be much larger than the number of generations for changes in population size to occur (ecological time, ca. 10 generations) (Hairston et al., 1970, and references cited therein). There is currently consensus that evolution can occur in a small number of generations: rapid evolution (Thompson, 1998; Hairston Jr. et al., 2005; Ellner et al., 2011; Galetti et al., 2013).

Finally, ecologists have always paid much more attention to the effects of proximate factors (biotic and abiotic factors that act contemporaneously on phenotypes) influencing the abundance and distribution of populations (e.g., Andrewartha \& Birch, 1954) than the possible effects of ultimate factors (or evolutionary factors). Most use proximate factors in a similar way to signify the influence of contemporary environmental factors on the response presented by organisms. Typical cases are physiological responses to environmental stimuli (e.g., hormonal changes in certain animals as a function of variation in day length) that promote behavioral changes (e.g., song of a bird emitted at the time of reproduction that attracts females to mate). On the other hand, these authors use ultimate factors only for the historical factors responsible for the adaptive responses that is evolved, presented by organisms. Ultimate factors are also used for explanations involving adaptive functions, that is, why morphological, physiological and behavioral traits are favored in terms of evolutionary fitness, and for historical factors that influenced the existence of evolutionary adaptations. Although both uses of the term seem reasonably clear, such characterizations still cause much confusion in the literature. For this reason, Haig (2013) proposed abandoning the expression ultimate factors because it is fraught with ambiguity and, thus, causes confusion in understanding the literature (to understand Haig's 
philosophical argument justifying the suggestion to abandon the use of the expression ultimate factors, I suggest reading the article).

Among the leading researchers who tried to integrate empirically and theoretically ecology and evolution are David Pimentel, G. Hutchinson, David Lack, William Hamilton, Stephen Stearns, Gordon Orians, Eric Pianka, John Endler, John Harper, Robert MacArthur, John Thompson, Joan Roughgarden and David Reznick. Since it is not possible to report here on each of these author's contributions, readers interested in delving into the subject will find sufficient material in the specialized literature and biographical descriptions on the Internet that exemplify their most relevant contributions. Nonetheless, it is worth mentioning Pianka (1974), a textbook that influenced the scientific course of several current evolutionary ecologists, as well as Fox et al. (2001), another more recent text, as two sources that provide broad conceptual and case study coverage. As the approach of the present text is conceptual, much of what will be shared here will come especially from Fox et al. (2001).

In a comprehensive approach, Collins (1986) analyzed the integration of ecology with evolution, that is, the use of natural selection in ecological theory (which today sounds a little strange, since natural selection is also an ecological theory) in two distinct historical periods - before 1950 and after 1960 with an intermediate period between 1950 and 1960 when there was a rapprochement between ecological theory and evolutionary theory. Before 1960, many ecologists believed in the integration of ecological theory and evolutionary theory, including Robert MacArthur (Collins 1986). However, they considered characteristics as adaptive due to their survival and/or reproduction value, without knowledge of their genetic basis, because at the time ecologists did not use the knowledge of evolutionary genetics.

Until 1920, the concern of some influential North American ecologists was the study of adaptations from an individual point of view, especially physiological adaptation (Kingsland, 2005). "Population thinking" (Hey, 2011) had not yet attracted much attention until beginning in 1960, when under the discussion of density-dependent and density-independent population regulation population ecology became grounded on "population thinking", but still without effective contact between evolutionary geneticists and population ecologists. However, there were already models describing how selection could work by regulating population size under the influence of density-dependence and density-independence (soft selection and hard selection, respectively).

An important example of this lack of more frequent effective contacts between ecology and population genetics is that of Lack (1965). Lack wrote an article featuring evolutionary ecology, which cites adaptations without any explicit linkage of population genetics to natural selection:" (1.) Evolutionary ecology addresses the problems concerning the number and distribution of animals (note that Lack excluded plants) for which explanations have to be sought in the evolutionary history of animals, that is, concentrated on ecological adaptations and their consequences. (2.) Interpretation of such adaptations can occur at two distinct levels - the level of physiological and behavioral mechanisms, and at the level of survival value (proximate and ultimate factors). (3.) The promoter agent of evolution is natural selection, and I see no need to posit the action of group selection for any ecological adaptation. (4.) Evolutionary ecology should primarily be studied in the natural habitat of the species, in which its adaptations have evolved. Many habitats have been modified by human action. (5.) Frequently one adaptive trait is closely linked to others so that effective changes in one needs changes in others. (6.) It is difficult to the survival value of many adaptive traits test in nature because variants that have been unsuccessful are usually eliminated by natural selection; furthermore, the production of experimentally abnormal variants may be impossible in the field and in the case of coexisting and hereditary normal variants, they are likely to be equally well adapted (if they were hereditary). (7.) Other variants are phenotypic and adapted to quite different circumstances, which may complicate the analysis of survival value, as exemplified by the survival of chicks relative to bird litter size. (8.) Frequently adaptive features studied in ecology are similar across all members so that their significance can be revealed by comparing them with different species. Given that adaptations are associated, such comparisons will be more revealing between closely related species than among remotely related species. (9.) As evolutionary ecology has to be studied primarily in natural habitats, there is an urgent need for conservation. (10.) Up to the present stage of evolutionary ecology, speculation is necessary, but it must first be confronted with experiences gained in the field". 
From the historiographical point of view there is some interest in confronting Lack's 10 suggestions on the characterization of evolutionary ecology with contemporary advances in this area of research. Thirty-six years after the publication of Lack (1965), for example, Fox et al. (2001) wrote: "In modern evolutionary ecology, adaptive traits and the evolvability of traits are hypotheses to be tested, rather than just presupposed a priori". Evolutionary ecologists, such as Lack, assumed that traits showing survival and/or reproduction value for the carrier phenotype should be adaptive. A priori assumptions of traits as adaptive were criticized by Gould \& Lewontin (1979), which resulted in modern evolutionary ecologists taking care to consider a priori assumptions as hypotheses whose predictions should be tested. However, Fox (2011) criticized the article by Gould \& Lewontin, considering it without solid argument and only a rhetorical and unnecessarily provocative piece. However, since the impact of the criticism of Gould \& Lewontin (1979) on the "adaptationist program" has been most striking, for those who wish to obtain more detailed and in-depth analysis of this controversy I suggest reading Pigliucci \& Kaplan (2006). Finally, I find it unnecessary to collate the other assumptions of Lack that would characterize evolutionary ecology, which today is, mainly with the advent of molecular genetics and ecology, at a much more advanced and detailed level of empirical and theoretical knowledge compared to the time when Lack formulated them, except that natural selection is still the process that produces adaptations.

\section{Basic Conceptual Framework of Evolutionary ECOLOGY}

Concepts are linguistic structures, with specific syntax and semantics, used as a means of communicating ideas. Concepts may be simple (e.g., tree), complex (e.g., adaptation) and part of a network of knowledge that characterizes an area of scientific research. Concepts are, therefore, fundamental structures of the framework of a theory (Pickett et al., 2007). They interact with the other structures of theory (e.g., hypotheses and evidence) in promoting consistency and likelihood to the predictions of hypotheses formulated from theoretical bases. For concepts to fulfill their function of brokering relations between other components of theory, they must be clearly defined so that they can be readily recognized in the different contexts in which they are to be used, otherwise, the theory may not reliably establish links between empirical evidence and the interpretation of the phenomena to which it refers.

The basic concepts of evolutionary ecology, their definitions, and the authors who defined them are set out in Table 1.

The interrelationships between the basic concepts that make up the conceptual framework of evolutionary ecology are shown in Figure 1.

Whether at local, regional or biogeographic scales, environmental conditions and resources act on the phenotypic and genotypic variation of a characteristic (e.g., bird beak) by selecting in the course of a generation individuals with traits (e.g., bird beak size), which may result in evolutionary adaptations over subsequent generations (which will depend on what happens during their genetic transmission). Therefore, traits that give individuals in a population greater relative chances of survival and reproduction positively influence their evolutionary fitness, which may result in population growth under certain environmental conditions and resources. This can happen

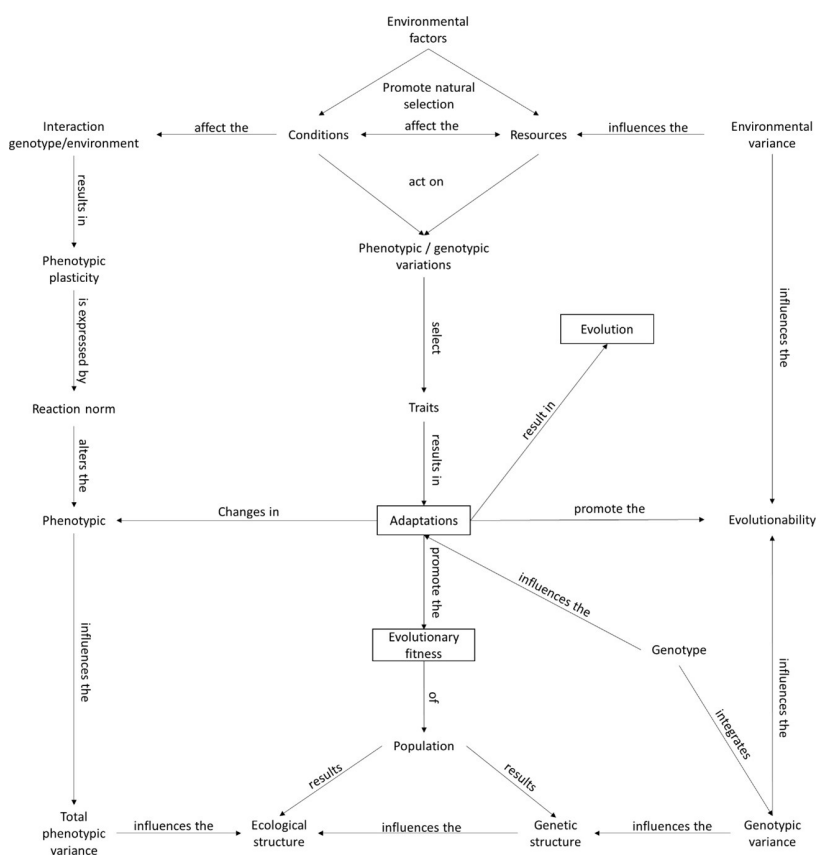

Figure 1: Conceptual map showing the relationships between concepts and processes that characterize the basic structure of evolutionary ecology. The environmental factors that are the selective agents are highlighted (diamond) at the beginning of the figure. Also included in the rectangular boxes are adaptations, which are the consequence of the actions of selective environmental factors evolutionary fitness, which is a consequence of adaptations; and evolution, which are the phenotypic changes consequent to adaptations (details in the text). Summarised and drawn by Rodrigo Massara. 
Table 1: The main concepts and basic processes in evolutionary ecology, the definitions of the concepts and the respective authors who formulated them.

\begin{tabular}{|c|c|c|}
\hline $\begin{array}{l}\text { Concepts and processes } \\
\text { of evolutionary ecology }\end{array}$ & Definitions & Authors \\
\hline Natural selection & $\begin{array}{l}\text { Process by which the action of environmental } \\
\text { factors favors phenotypic variations that give their } \\
\text { carriers greater relative probabilities of survival and } \\
\text { reproduction }\end{array}$ & The author of this text. \\
\hline Environmental factors & $\begin{array}{l}\text { Physicochemical conditions of the environment, } \\
\text { food resources, breeding sites, interactions between } \\
\text { individuals and species that influence the evolution of } \\
\text { adaptations }\end{array}$ & The author of this text. \\
\hline Environmental conditions & $\begin{array}{l}\text { Abiotic and biotic variables that are vectors of natural } \\
\text { selection acting on phenotypic variation }\end{array}$ & The author of this text. \\
\hline Usable resources & $\begin{array}{l}\text { Proportion of food items and breeding sites used by } \\
\text { individuals in a population in a given community }\end{array}$ & The author of this text. \\
\hline Evolutionary adaptations & $\begin{array}{l}\text { Results of selection action on population phenotypic and } \\
\text { genotypic variation }\end{array}$ & The author of this text. \\
\hline Phenotypic variation & $\begin{array}{l}\text { Refers to morphological or physiological plasticity or } \\
\text { phenotypic changes caused by environmental variation }\end{array}$ & $\begin{array}{l}\text { Abrams (1993) with } \\
\text { modification }\end{array}$ \\
\hline Genotypic variation & Genetic differences among individuals of a population & Abrams (1993) \\
\hline Population thinking & $\begin{array}{l}\text { Expression attributed to evolutionary ecological studies } \\
\text { that focus on understanding phenotypic and genotypic } \\
\text { variation of populations }\end{array}$ & The author of this text. \\
\hline Statistical population & $\begin{array}{l}\text { Consists of samples taken from a real population to test } \\
\text { the likelihood that they are legitimate representatives of } \\
\text { the real population }\end{array}$ & The author of this text. \\
\hline $\begin{array}{l}\text { Proximal population } \\
\text { structure }\end{array}$ & $\begin{array}{l}\text { Normally refers to the frequency of certain ages or sexes } \\
\text { in a population }\end{array}$ & Nunney (2001) \\
\hline Panmictic population & A large population of individuals who mate at random & The author of this text. \\
\hline Structured population & $\begin{array}{l}\text { A small population, compared to a panmictic population, } \\
\text { in which mating is preferential }\end{array}$ & The author of this text. \\
\hline Evolutionary fitness & $\begin{array}{l}\text { Differential survival and reproduction among } \\
\text { individuals of a population }\end{array}$ & The author of this text. \\
\hline Evolvability & $\begin{array}{l}\text { Capacity of a population to evolve under certain } \\
\text { environmental conditions }\end{array}$ & The author of this text. \\
\hline
\end{tabular}


Table 1, continued

\begin{tabular}{|c|c|c|}
\hline $\begin{array}{l}\text { Concepts and processes of } \\
\text { evolutionary ecology }\end{array}$ & Definitions & Authors \\
\hline Characteristic & Any structure, function or behavior of a phenotype & The author of this text. \\
\hline Trait & The same as characteristic & The author of this text. \\
\hline Total phenotypic variance & $\begin{array}{l}\text { Estimated variance of traits of all phenotypes } \\
\text { measured in a population }\end{array}$ & Mazer \& Damuth (2001) \\
\hline Additive genetic variance & $\begin{array}{l}\text { Proportion of total phenotypic variance of a } \\
\text { trait due to the additive effect of nuclear genes } \\
\text { (heritability) }\end{array}$ & Mazer \& Damuth (2001) \\
\hline Non-additive genetic variance & $\begin{array}{l}\text { Proportion of the total phenotypic variance of a } \\
\text { trait that cannot be predicted from the combined } \\
\text { additive effects of nuclear alleles of a genotype. It } \\
\text { may occur through dominance or epistasis. }\end{array}$ & Mazer \& Damuth (2001) \\
\hline $\begin{array}{l}\text { Non-additive variance by } \\
\text { dominance }\end{array}$ & $\begin{array}{l}\text { Can be identified when alleles at a single locus } \\
\text { interact to produce a phenotype which cannot be } \\
\text { predicted from the effects produced on average by } \\
\text { the influence of those alleles acting alone. }\end{array}$ & Mazer \& Damuth (2001) \\
\hline $\begin{array}{l}\text { Non-additive variance by } \\
\text { epistasis }\end{array}$ & $\begin{array}{l}\text { When the phenotypes or evolutionary fitness of a } \\
\text { genotype at a locus depends on the genotype of one } \\
\text { or more loci }\end{array}$ & $\begin{array}{l}\text { Mazer \& Damuth (2001) } \\
\text { with modification }\end{array}$ \\
\hline Pleiotropy & $\begin{array}{l}\text { Occurs when an individual gene influences } \\
\text { multiple aspects of an organism }\end{array}$ & Reznick \& Travis (2001) \\
\hline Adaptive pleiotropy & $\begin{array}{l}\text { When the pleiotropic effect benefits the } \\
\text { evolutionaryfitnessof an individual }\end{array}$ & The author of this text. \\
\hline Antagonistic pleiotropy & $\begin{array}{l}\text { When a gene controls the expression of more than } \\
\text { one trait, and one trait is beneficial and another } \\
\text { is detrimental to the evolutionary fitnessof an } \\
\text { individual }\end{array}$ & The author of this text. \\
\hline Environmental variance & $\begin{array}{l}\text { Determines howmuch variation intraitsof } \\
\text { the phenotype or genotype is due to direct } \\
\text { environmental influence (see phenotypic plasticity) }\end{array}$ & The author of this text. \\
\hline $\begin{array}{l}\text { Genotype } \mathrm{x} \text { environment } \\
\text { interaction }\end{array}$ & $\begin{array}{l}\text { Occurs when genotypes differ in their phenotypic } \\
\text { responses as a function of environmental } \\
\text { conditions and resources }\end{array}$ & $\begin{array}{l}\text { Mazer \& Damuth (2001b) } \\
\text { with modification }\end{array}$ \\
\hline Phenotypic plasticity & $\begin{array}{l}\text { Property of a genotype in producing different } \\
\text { phenotypes in response to different environmental } \\
\text { conditions }\end{array}$ & Pigliucci (2001) \\
\hline Reaction norm & $\begin{array}{l}\text { Different values that the same trait in different } \\
\text { individuals can assume in a gradient of } \\
\text { environmental variation }\end{array}$ & Pigliucci (2001) \\
\hline Genetic structure of populations & $\begin{array}{l}\text { Occurs as a result of aggregations of individuals } \\
\text { originating from the same descent or through } \\
\text { spatial variation in the action of selection on a } \\
\text { population }\end{array}$ & $\begin{array}{l}\text { Mazer \& Damuth (2001) } \\
\text { with modification }\end{array}$ \\
\hline $\begin{array}{l}\text { Ecological structure of } \\
\text { populations }\end{array}$ & $\begin{array}{l}\text { Occurs due to the differential distribution of } \\
\text { individuals of different ages or sexes }\end{array}$ & The author of this text. \\
\hline
\end{tabular}


either in a panmictic population (large population with random mating), or in ecologically and genetically structured populations in which preferential mating may occur.

Random changes in allele frequencies are more likely to occur by genetic drift in small genetically structured populations. Small, viscous populations (structured populations in which individuals have low dispersibility) will have reduced gene flow and low local genetic variance. One consequence of this aggregation of individuals is the greater likelihood of inbreeding further reducing genetic variance, thereby decreasing the ability of populations to evolve (evolvability). The risk of extinction for populations with these characteristics is considerable, making them vulnerable and in need of management and conservation, especially those populations in areas where habitat destruction is intense or in limited ecological reserves, among which there are no ecological corridors. Such corridors may, in some cases, be important for linking reserves of limited size to larger reserves or continuous source areas from which gene flow can occur and maintain genetic variability. However, if the population structure is metapopulational (sets of populations that remain structured through a balance between migration and extinction), local extinctions may occur due to random factors that alter, for example, balanced sex ratio (diseases that affect only males, for example). The areas that these extinct populations occupied may be repopulated through colonization by migrants from adjacent populations, thereby maintaining the metapopulational structure, which may be important form a conservation point of view.

Genotype/environment interactions can determine the occurrence of phenotypic plasticity and the respective reaction norms in a gradient of environmental heterogeneity. Although the environment directly influences the occurrence of phenotypic plasticity, phenotypic plasticity must have a genetic basis in order to be evolutionarily adaptive. However, not all plasticity will be adaptive; it may also be neutral or even maladaptive due to the costs and limits imposed on the development of an individual (see Martins, 2018, and references therein) in the generation of an optimized trait or phenotype (trait that gives the organism a better performance relative to the other similar traits in individuals in a population). For example, a bird that has a larger sized beak than other birds in a population will be more efficient at using a particular type of resource and may be more likely to survive and reproduce than individuals in the same population that have medium or small sized beaks. Therefore, again, adaptations can positively influence individual fitness and promote population growth in ecologically stable and unstable environments.

When adaptive, phenotypic plasticity can increase total phenotypic variance resulting in a greater ability to evolve in heterogeneous environments in which environmental conditions vary. In turn, genotypic variance may influence the genetic structure of the population, such as in viscous populations or populations in which size has been drastically reduced and they have become isolated (e.g., due to the occurrence of environmental catastrophe). Genetic variance may be reduced if the area in which a population is distributed is not colonized by individuals from adjacent populations. Thus, it is important to maintain gene flow between populations because it increases and maintains the genotypic variability of the population, increases the probability of evolvability of the population, influences the genetic structure of the population and decreases the chances that it will become locally extinct.

On the other hand, as is well known, mutations are the primary source of variation on which environmental factors act primarily by selecting phenotypes with higher relative fitness in the population. However, although they may have lower relative fitness, certain phenotypes are also retained in the population as they also survive and reproduce, thereby helping to maintain the phenotypic and genotypic variability of the population. Genotypic variability, in addition to relying on recombination and other genetic mechanisms for its maintenance, is influenced by additive genetic variance, which is responsible for phenotypic similarities between progenitors and offspring (e.g., univitelline twins may have high heritability of traits of one or both of the progenitors), nonadditive genetic variance (dominance and epistasis) and pleiotropy. When dominance is present, predictability of parent-descendant similarity becomes even more uncertain compared to those in which allelic dominance does not exist. Similarly, when epistasis occurs, the predictability of similarity can also be decreased, as also occurs with antagonistic pleiotropy. However, in the case of nonadditive variance, only when careful mating experiments can be performed will there be a chance to distinguish between dominance and epistasis, which is generally not the case in the types of experiments conducted by evolutionary ecologists (Mazer \& Damuth, 2001b). Regarding the evolution- 
ary consequences of pleiotropy, its occurrence may be beneficial to individual evolutionary fitness, as in the case of adaptive pleiotropy, or detrimental, as in the case of antagonistic pleiotropy. However, epistasis, dominance and pleiotropy are complex concepts that address not only a single gene and its effects on the phenotype, but also refer to the role of gene groups or gene complexes. For more detail on this conceptual complexity I suggest consulting Pigliucci \& Kaplan (2006).

\section{Conclusions}

The conceptual interrelationships, and some evolutionary consequences of these interrelationships, which make evolutionary ecology an important area of research in evolutionary biology, have been addressed here. Theoretical research in evolutionary ecology is also very important as it substantially extends knowledge about the evolution of populations in stable environments and populations subject to random or periodic instabilities. However, while providing predictions that are logical and consistent with current knowledge, these predictions are produced in silico. Therefore, the theoretical assumptions coming from models must be validated in the field, where real populations actually evolve under the action of multiple factors, environmental conditions and available resources, which are ultimately the selective agents that promote adaptations and the evolutionary fitness of individuals who integrate them.

In part, due to the successful theoretical development (mathematical and statistical modeling) of evolutionary ecology, field research on the natural history of populations has had its status reduced, although it is essential to support the formulation of ecological-evolutionary hypotheses and the extraction of their respective predictions, which will be confronted through experiments and field observations. From this perspective, all case studies exemplified in Fox et al. (2001) have a substantial base of information about the natural history of the interactive systems studied, showing that this fundamental knowledge has been, and certainly will continue to be, of great importance in the development of evolutionary ecology. Therefore, as part of the training of evolutionary ecologists, an emphasis should be made on field training (observations, hypothesis formulation and experiments) in undergraduate and graduate courses in biology.

\section{ACKNOWLeDGeMents}

Ricardo Solar, Ricardo Iglésias, Fabrício Santos, Frederico Neves and Marcos Callisto contributed to improving the understanding of the text. Rodrigo Massara executed the concept map art and translated the abstract. Erik Wild translated the text. The Brazilian National Council of Research and Technology Development (CNPq) granted a visiting researcher scholarship in Departamento de Biologia, Programa de Pós-Graduação em Ecologia e Recursos Naturais (PPGERN), Universidade Federal do Ceará (UFC).

\section{REFERENCES}

Abrams, M. C. (1993). Genotypic and phenotypic variation as stress adaptation in temperate tree species: a review of several cases studies. Tree Physiology, 14, 833-842.

Andrewartha, H.G. \& Birch, L.C. (1954) The Abundance and Distribution of Animals. Chicago: University of Chicago Press.

Brodie III, E. D., Moore, A. J. \& Janzen, F. J. (1995). Visualizing and measuring natural selection. Trends in Ecology and Evolution, 10, 313-318.

Charlesworth, D., Barton, N. H. \& Charlesworth, B. (2017). The sources of adaptation. Proceedings of the Royal Society of London B, 284, 20162864. http:// dx.doi.org/10.1098/rspb.2016.2864.

Collins, J. P. (1986). "Evolutionary Ecology" and the use of natural selection in ecological theory. Journal of History of Biology, 19, 257-288.

Darwin, C. R. (1990). The origin of species by means of natural selection, or the preservation of favoured races in the struggle for life. Chicago: Encyclopedia

Britannica, Inc.

Débarre, F. \& Gandon, S. (2011). Evolution in heterogeneous environments: Between soft and hard selection. The American Naturalist, 177, E84-E97.

Dunn, P. M. (2006). Aristotle (384-322 BC): philosopher and scientist of ancient Greece. Archives of the Disorders Child Fetal Neonatal, 91, 75-77.

Ellner, S. P., Geber, M. A. \& Hairston, N. G. Jr. (2011). Does rapid evolution matter? Measuring the rate of contemporary evolution and its impacts on ecological dynamics. Ecological Letters, 14, 603-614.

Endler, J. A. (1986). Natural Selection in the Wild. New Jersey: Princenton University Press.

Fox, C. W., Roff, D. A. \& Fairbairn, D. I., (eds.) (2001). Evolutionary ecology - Concepts and Case Studies. London: Oxford University Press. 
Fox, J. (2011). Why the sprandels of San Marco isn't a good paper? https://oikosjournal.wordpress. com/2011/08/26/why-the-spandrels-of-san-marcoisnt-a-good-paper/.

Fairbarn, D. J. \& Reeve, J. P. (2001). Natural Selection. Pp. 29-43, in: Fox, C. W., Roff, D. A. \& Fairbairn, D. J., (eds.). Evolutionary Ecology - Concepts and Case Studies. London: Oxford University Press.

Galetti, M., Guevara, R., Côrtes, M. C., Fadini, R., Von Mater, S., Leite, A. B., Labecca, F. M., Ribeiro, T., Carvalho, C. S., Collevatti, R. G., Pires, M., Guimarães, P. R., Brancalion, P. H. S., Ribeiro, M. C., Jordano, P. (2013). Functional extinction of birds drives rapid evolutionary changes in seed size. Science, 340, 1086-1090.

Gould, S. J. \& Lewontin, R. C. (1979). The spandrels of San Marco and the Panglossian paradigm: a critique of the adaptationist programme. Proceedings of the Royal Society of London B, 205, 581-598.

Haig, D. (2013). "Proximate and ultimate causes: How come? and what for?" Biology and Philosophy, 28, 781-786.

Hairston Jr., N. G., Tinkle, D. W. \& Wilbur, H. W. (1970). Natural selection and the parameters of population growth. Journal of Wildlife Management, 34, 681690.

Hairston Jr., N. G., Ellner, S. P., Geber, M. A., Yoshida, T. \& Fox, J. A. (2005). Rapid evolution and the convergence of ecological and evolutionary time. Ecological Letters, 8, 1114-1127.

Hey, J. (2011) Regarding the confusion between the population concept and Mayr's "population thinking”. Quartely Review of Biology, 86, 253-264.

Kingsland, S. E. (2005). The Evolution of American Ecology-1890-2000. Baltimore: John Hopkins University Press,

Martins, R. P. \& Barbeitos, M. S. (2000). Adaptações de insetos a mudanças no ambiente: ecologia e evolução da diapausa. Pp. 149-192, in: Martins, R. P., Lewinsohn,

T. M. \& Barbeitos, M. S., (eds.). Ecologia e Comportamento de Insetos. Série Oecologia Brasiliensis, vol. VIII, PPGR-UFRJ, Rio de Janeiro.

Martins, R.P., Guerra, S.T.M. \& Barbeitos, M. S. (2001). Variability in egg-to-adult development time in the bee Ptilothrix plumata and its parasitoids. Ecological Entomology, 26, 609-616.

Martins, R. P. \& Almeida, D. A. O. (1994). Is the bee, Megachile assumptionis (Hymenoptera: Megachilidae), a cavity-nesting specialist? Journal of Insect Behavior, 7, 759-765.
Martins, R. P., Tidon, R. \& Diniz-Filho, J. A. F. (2017). The evolutionary ecology of interactive synchronism: the illusion of the optimal phenotype. European Journal of Ecology, 3, 107-115.

Martins, R. P. (2018). The conceptual structure of evolutionary biology: A framework from phenotypic plasticity. European Journal of Ecology, 4, 111-123.

Mayr, E. \& Provine, W. B. (eds.) (1998) The Evolutionary Synthesis. Cambridge: Harvard University Press.

Mazer, S. J \& Damuth, J. (2001). Evolutionary significance of variation. Pp. 16-28, in: Fox, C. W., Roff, D. A. \& Fairbairn, D. I., (eds.). Evolutionary Ecology - Concepts and Case Studies. London: Oxford University Press.

Moen, D. S., Irschick, D. J. \& Wiens, J. J. (2013). Evolutionary conservatism and convergence both lead to striking similarity in ecology, morphology and performance across continents in Frogs. Proceedings of the Royal Society of London B: Biological Sciences, 280, 20132156.

Moure, J. S. \& Melo, G. A. R. (2012). Emphorini Robertson, 1904. In: Moure, J. S., Urban, D. \& Melo, G. A. R. (Orgs). Catalogue of Bees (Hymenoptera, Apoidea) in the Neotropical Region - online version. Available at http://www.moure.cria.org.br/catalogue. Accessed Dec/05/2019.

Nikishawa, K. \& Kino, A. R. (2018) Mechanism of evolution by genetic assimilation. Biophysical Review, 10, 667-676.

Pianka, E. R. (1974). Evolutionary Ecology. New York: Harper and Row.

Pickett, S.T. A., Jones, C. G. \& Kolassa, J. (2007). Ecological Understanding: The Nature of Theory and the Theory of Nature. New York: Academic Press.

Pigliucci, M. (2001). Phenotypic plasticity. Pp. 58-69, in: Fox, C. W., Roff, D. A. \& Fairbairn, D. I. (eds.). Evolutionary Ecology - Concepts and Case Studies. London: Oxford University Press.

Osborn, R. F. (1913). From the greeks to Darwin - An Outline of the Development of the Evolution Idea. London: Forgotten Books.

Pigliucci, M. \& Kaplan, J. (2006). Making Sense of Evolution - The Conceptual Foundations of Evolutionary biology. Chicago: Chicago University Press.

Reznick, D. (2016). Hard and soft selection revisited: How evolution by natural selection works in the real world. Journal of Heredity, 107, 3-14.

Silveira, F. A., Melo, G. A. R. \& Almeida, E. A. B. (2002). Abelhas Brasileiras - Sistemática e identificação. Belo Horizonte: edição do autor, 2002. 
Thompson, J. M. (1998). Rapid evolution as an ecological process. Trends in Ecology and Evolution, 13: 329-332.

Trevisanato, S. I. (2016). Reconstructing Anaximander's biological model unveils a theory of evolution akin to Darwin's, though centuries before the birth of science. Acta Medica Historica Adriatica, 14, 63-72.

Wolf, J. B. \& Wade, M. J. (2009). What are maternal effects (and what are they not)? Philosophical Transactions of the Royal Society of London B, 364, 1107-1115. 